\title{
Is S1 Alar Iliac Screw a Feasible Option for Lumbosacral Fixation?: A Technical Note
}

\author{
Zhi Wang ${ }^{1}$, Ghassan Boubez ${ }^{1}$, Daniel Shedid ${ }^{2}$, Sung Jo Yuh ${ }^{2}$, Amer Sebaaly ${ }^{1,2,3}$ \\ ${ }^{1}$ Department of Orthopedic Surgery, Spine Unit, Centre Hopitalier de l'Université de Montréal, Montréal, Canada \\ ${ }^{2}$ Department of Neurosurgery, Spine Unit, Centre Hopitalier de l'Université de Montréal, Montréal, Canada \\ ${ }^{3}$ Faculty of Medicine, Saint Joseph University, Beirut, Lebanon
}

Nonunion at the lumbosacral junction is a classic complication of long construct and deformity corrections. Iliac fixations have been extensively studied in the literature and have demonstrated superior biomechanical proprieties and lower complication rates. S2 alar iliac screws address the drawbacks of classical iliac screws but demonstrate similar biomechanical advantage. The main aim of this paper was to describe the S1 alar iliac (S1Al) screw fixation technique while evaluating our early results. S1Al screw fixation technique has the advantage of being able to achieve pelvic fixation without dissection to the S2 pedicle entry and is therefore a viable option for salvage of a failed S1 promontory screw.

Keywords: Lumbopelvic fixation; Pseudarthrosis; Lumbosacral region

\section{Introduction}

Adult spinal deformity surgery is associated with high rates of mechanical complications, such as proximal junctional kyphosis and nonunion [1]. Nonunion at the lumbosacral junction is a classic complication of long construct, with the reported incidence of nonunion ranging from $5 \%$ to $44 \%$ when using $\mathrm{S} 1$ promontory screws (classical S1 screws) [2-4]. The risk of nonunion increases with fusions extending to L3 and above [5]. Therefore, experts have recommended anterior interbody support or iliac fixation to decrease the risk of nonunion $[6,7]$. Furthermore, addition of anterior support without pelvic fixation does not decrease the stress on the S1 screws [5]. Classical iliac fixation has been extensively studied and has demonstrated superior biomechanical proprieties and lower pseudarthrosis rates than those of the Galveston technique or sacral plate technique [4]; however, its drawbacks include separate skin incision, use of connectors, and development of implant prominence requiring screw removal (range, $22 \%-34 \%$ ) $[4,5,8]$. The use of S2 alar iliac (S2AI) screws in pediatric patients has been popularized by Paul D. Sponseller and in adult patients by Khaled M. Kebaish [9]. S2AI screws address the drawbacks of classical iliac screws while demonstrating similar biomechanical advantages [9].

To the best of our knowledge, there is no description of iliac fixation emerging from the first sacral pedicle. The S1 alar iliac (S1AI) screw has the advantage of achieving pelvic fixation without dissection to the S2 pedicle entry

\footnotetext{
Received Oct 6, 2017; Revised Nov 2, 2017; Accepted Nov 26, 2017

Corresponding author: Amer Sebaaly

Department of Orthopedic surgery, Spine Unit, Centre Hopitalier de l'Université de Montréal, Hôpital Notre Dame, Rue Sherbrooke, Montréal, QC, H2L 4M1, Canada

Tel: +1-514-586-4860, E-mail: amersebaaly@hotmail.com
} 


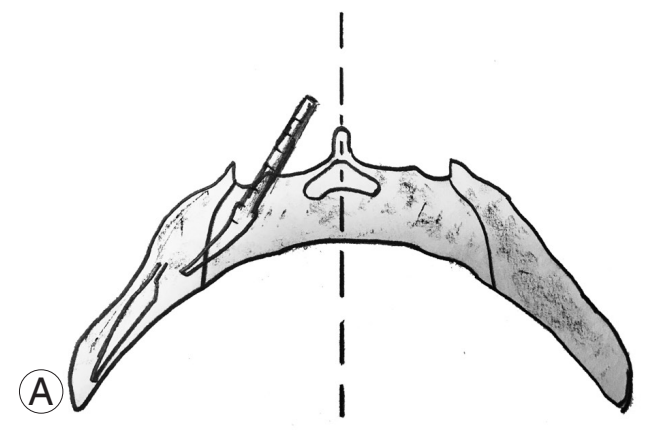

(B)

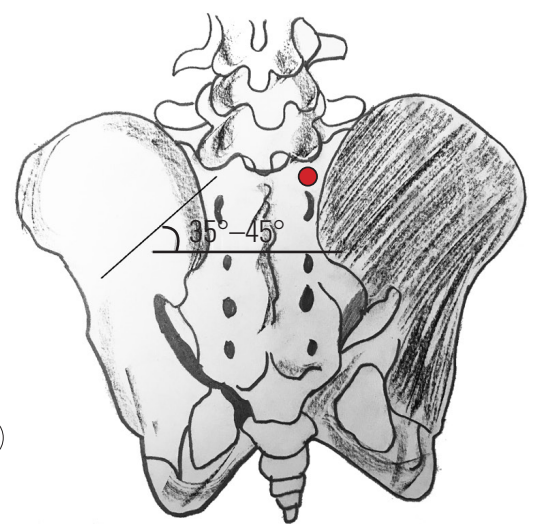

Fig. 1. (A) Axial drawing showing the direction of the probe in the sacral and iliac bone. (B) Drawing showing the entry point (red dot) as well as the caudal direction of the screw $\left(35^{\circ}-45^{\circ}\right)$. and may be a viable option for the salvage of a failed S1 promontory screw. The main aim of this paper was to describe the S1AI screw fixation technique and report our experience with the first few cases.

\section{Technical Note}

S1AI screw fixation is performed using anatomical landmarks and under fluoroscopic guidance. The entry point is located at the entry of the S1 pedicle at the foot of the superior S1 facet in the middle (Fig. 1). The entry point should not be located very laterally (to have sufficient purchase in the sacrum) or medially (to be in line with the L5 screws). A 2-mm burr is used to create a posterior breach for the entry point. The gear shift is pointed backward to avoid anterior sacral breach. The gear point is angled $35^{\circ}-$ $45^{\circ}$ caudally and $20^{\circ}$ horizontally in the coronal plane. The position is checked using anteroposterior (AP) fluoroscopy such that the screw should aim at the ipsilateral greater trochanter (Fig. 2). The pedicle finder is advanced $3-5 \mathrm{~cm}$ until it hits the lateral sacral cortex at the sacroiliac joint. The sacroiliac joint is penetrated by carful advancement of the pedicle finder, either manually or using
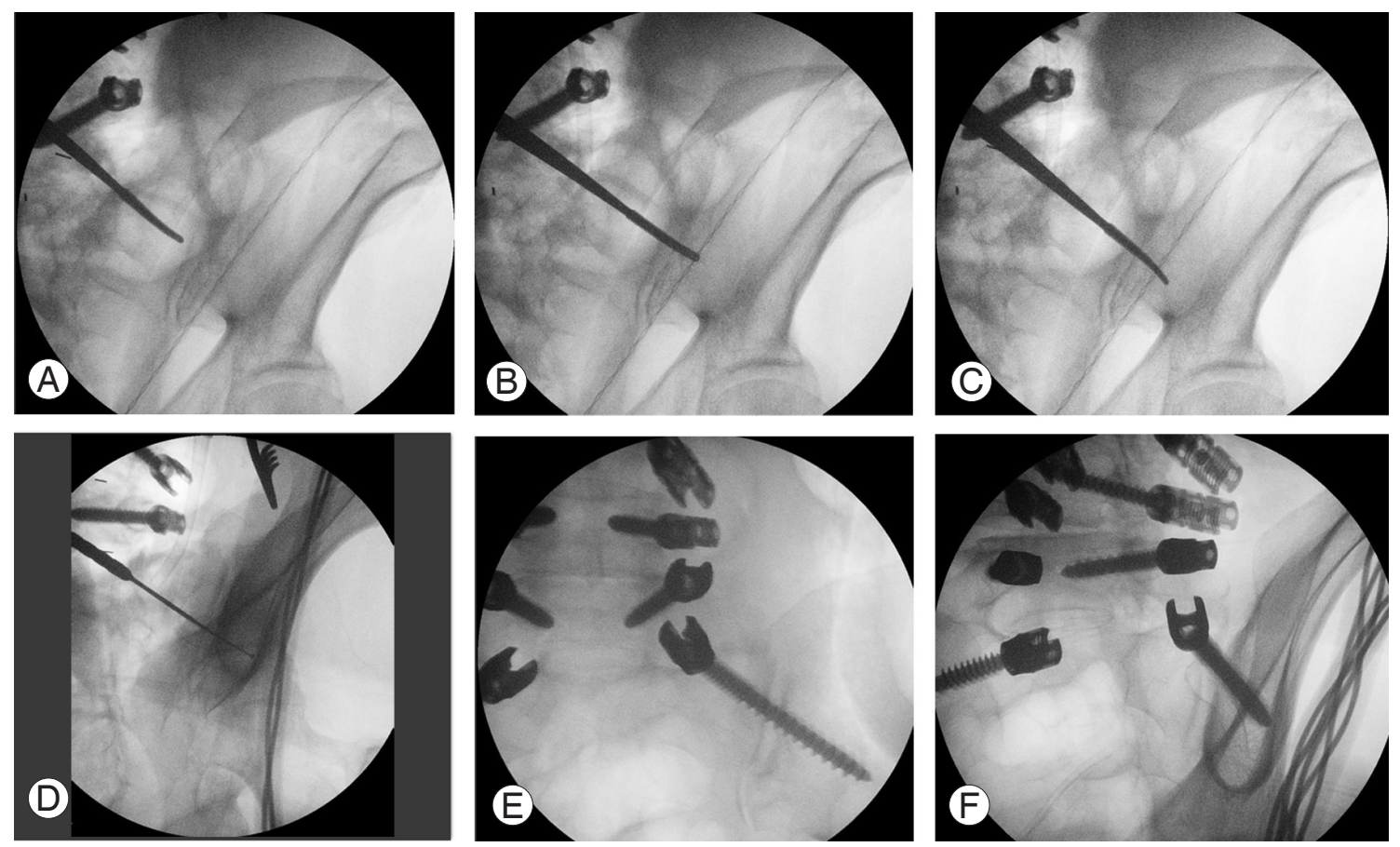

Fig. 2. (A) Steps for S1 alar iliac implementation. The probe is against the sacroiliac joint. (B) Probe is advanced through the sacroiliac joint. (C) Probe is turned $180^{\circ}$ and advanced in the iliac bone. (D) The ball-tipped feeler is used to detect the bony borders. A tear drop view is used for checking the final position. (E) Final position in the anteroposterior view. (F) Final position in the tear drop view. 

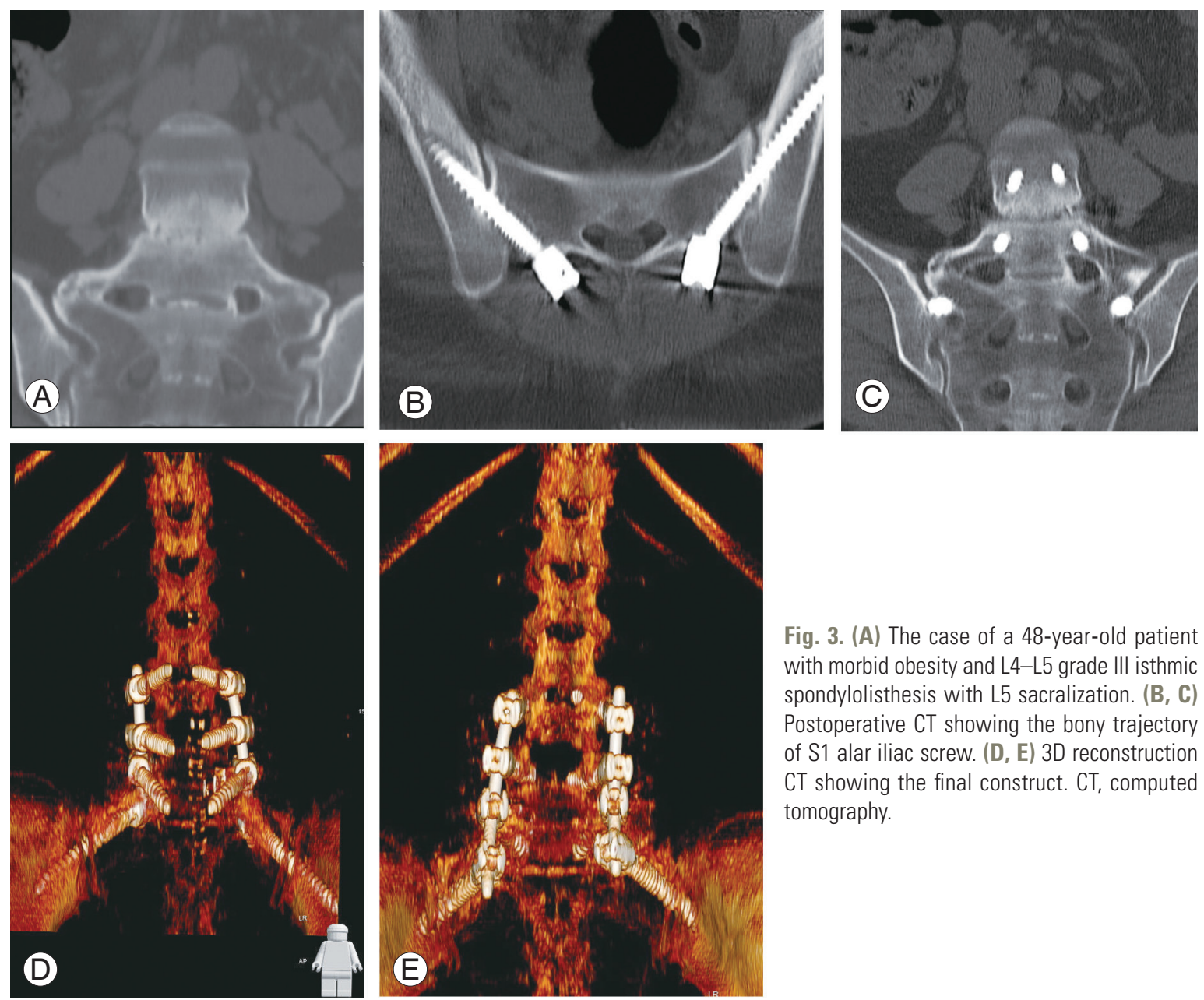

Fig. 3. (A) The case of a 48-year-old patient with morbid obesity and $\mathrm{L} 4-\mathrm{L} 5$ grade III isthmic spondylolisthesis with $\mathrm{L} 5$ sacralization. $(\mathbf{B}, \mathbf{C})$ Postoperative CT showing the bony trajectory of S1 alar iliac screw. (D, E) 3D reconstruction CT showing the final construct. CT, computed tomography.

a mallet hammer, after determining the correct position using AP fluoroscopy. The curved probe is turned $180^{\circ}$ to face anteriorly. The use of a long probe with a straight handle to maintain the $20^{\circ}$ horizontal coronal angle and minimize the interference of surrounding tissues is preferred. Oblique fluoroscopy with tear drop view is used to verify the intrapelvic trajectory of the tip of the gear shift after advancing $5 \mathrm{~mm}$ into the iliac bone until the desired depth is achieved (normally $\geq 75 \mathrm{~mm}$ ). Next, a ball-tipped sounding device is used to palpate all bony borders, after which tapping and screw insertion is performed in the classical manner.

Between June 2017 and September 2017, seven patients were operated using S1AI screw fixation. The use of S1AI screw fixation was indicated by sacralization of L5 with high grade isthmic spondylolisthesis in one patient, severe S1 body osteoporosis with a history of anterior surgery on the sacral plateau in one, spinal metastasis to the L5 body requiring L5 corpectomy and pelvic fixation in two, pelvic fixation for $\mathrm{L} 2-\mathrm{S} 1$ construct in two, and nonunion at the lumbosacral junction in one. Postoperative pelvic computed tomography and evaluation of the screw trajectory and ilium size were performed.

A total of 14 S1AI screws were placed and evaluated using postoperative imaging. The mean length and diameter of the S1AI screws were $78 \mathrm{~mm}$ and $8 \mathrm{~mm}$, respectively. There were three posterior cortical breaches of the iliac bone that were observed in the first two cases in which we used a straight gear probe. The average length of the screw inside the iliac bone was $37.3 \mathrm{~mm}$. There were no patients with neurological or vascular complications associated with the use of these screws. No patients presented postoperative sacroiliac pain during the short follow-up period.

\section{Discussion}

Even with the advancement of spinal instrumentation, 
the incidence of mechanical complications is up to $44 \%$. Therefore, distal fixation for long posterior spinal fixation is crucial [2]. Kim et al. [10] found that the L5-S1 space is the most common site for nonunion during scoliosis surgery, with an incidence of $24 \%$. The use of pelvic fixation as an adjunct for sacral fixation decreased the incidence of mechanical complications at the sacroiliac junction to $<5 \%$ [8]. Nonetheless, iliac screws are associated with extensive tissue dissection, connector use, and implant prominence development $[3,8]$. S2AI screw fixation has been described as an alternative to iliac fixation, with the biomechanical advantage of cortical fixation (both sides of the sacroiliac joint) as well as cancellous purchase in the narrow space between the two cortices of the iliac wing. We described, for the first time, S1 alar iliac direction for sacropelvic fixation. This fixation technique could be used in patients with abnormal transition at the lumbosacral area (sacralization of L5) (Fig. 3). In our opinion, the most important indication for using S1AI screw fixation was to salvage S1 screw failure (loose classical S1 screw, destruction of the anterior sacral body by a tumor, etc.). Generally, osteopenia at S1 limits the quality of fixation at the S1 promontory screw.

The advantages of the newly described S1AI screw fixation are numerous. It is in line with other screws and does not require connectors. There is less need for extensive dissection of the sacral ala because the entry point is more medial than that in classical sacral screw fixation, thereby reducing bleeding and operative time. In addition, this type of trajectory offers the advantages of pelvic fixation. Moreover, as shown by Sutterlin et al. [5], the use of pelvic fixation as an adjunct to a long construct is superior to using an anterior support alone.

The incidence of posterior breach was $21 \%$, and a straight probe was used in all such cases. In case of S2AI screws, this breach frequently ranged between $10 \%$ and $22 \%$ [2]. Several studies have shown that the "four wall cortical" purchase was superior to the "three wall cortical" purchase with S2AI screws [11]. Nonetheless, the use of quad cortical purchase has been debated and lacks supportive evidence [2]. Albeit this controversy, the posterior breach was not associated with increased vascular or neurological complications.

Several studies have shown that sacroiliac pain is one of the leading causes of failed back surgery syndrome, with an estimated incidence of $22 \%-40 \%$ [12]. One notable concern was that the S1AI screw crossed the sacroiliac joint. In fact, O'Brien et al. [3] found that the S2AI screw crossed the SI joint cartilage in $60 \%$ of cases in a cadaveric study. The long-term effects of this breach are not fully known, and longer follow-ups of patients with S2AI screw fixation may elucidate this issue. Nonetheless, the incidence of SI joint pain seems to be relatively low with the use of S2AI screws [2]. This could be caused by the fixation of the SI joint by the traversing screw [13].

This technical note reported the first few experiences of the use of S1AI screws. There were several limitations in this study. First, there was no long term follow-up to evaluate the screw performance. Second, there are no biomechanical studies that proved the superiority of this screw type over S1 promontory screws. To overcome the second limitation, an ongoing biomechanical study has been designed.

In conclusion, the use of S1AI screw fixation is a viable option that may serve as a foundation for long constructs. Its main advantage is its suitability for revision surgery for failed lumbo-sacro-pelvic fixation. It can also be used in patients with weak S1 promontory fixation, especially in those with osteoporosis. However, further biomechanical testing and longer follow-ups are needed.

\section{Conflict of Interest}

No potential conflict of interest relevant to this article was reported.

\section{References}

1. Sebaaly A, Riouallon G, Obeid I, et al. Proximal junctional kyphosis in adult scoliosis: comparison of four radiological predictor models. Eur Spine J 2018;27:613-21.

2. Park YS, Hyun SJ, Park JH, Kim KJ, Jahng TA, Kim HJ. Radiographic and clinical results of freehand S2 alar-iliac screw placement for spinopelvic fixation: an analysis of 45 consecutive screws. Clin Spine Surg 2017;30:E877-82.

3. O’Brien JR, Yu WD, Bhatnagar R, Sponseller P, Kebaish KM. An anatomic study of the S2 iliac technique for lumbopelvic screw placement. Spine (Phila Pa 1976) 2009;34:E439-42.

4. Finger T, Bayerl S, Onken J, Czabanka M, Woitzik J, Vajkoczy P. Sacropelvic fixation versus fusion to the sacrum for spondylodesis in multilevel degenerative 
spine disease. Eur Spine J 2014;23:1013-20.

5. Sutterlin CE 3rd, Field A, Ferrara LA, Freeman AL, Phan K. Range of motion, sacral screw and rod strain in long posterior spinal constructs: a biomechanical comparison between S2 alar iliac screws with traditional fixation strategies. J Spine Surg 2016;2:266-76.

6. Chang TL, Sponseller PD, Kebaish KM, Fishman EK. Low profile pelvic fixation: anatomic parameters for sacral alar-iliac fixation versus traditional iliac fixation. Spine (Phila Pa 1976) 2009;34:436-40.

7. Harimaya K, Mishiro T, Lenke LG, Bridwell KH, Koester LA, Sides BA. Etiology and revision surgical strategies in failed lumbosacral fixation of adult spinal deformity constructs. Spine (Phila Pa 1976) 2011;36:1701-10.

8. Tsuchiya K, Bridwell KH, Kuklo TR, Lenke LG, Baldus C. Minimum 5-year analysis of L5-S1 fusion using sacropelvic fixation (bilateral S1 and iliac screws) for spinal deformity. Spine (Phila Pa 1976) 2006;31:303-8.
9. Jain A, Hassanzadeh H, Strike SA, Menga EN, Sponseller PD, Kebaish KM. Pelvic fixation in adult and pediatric spine surgery: historical perspective, indications, and techniques: AAOS exhibit selection. J Bone Joint Surg Am 2015;97:1521-8.

10. Kim YJ, Bridwell KH, Lenke LG, Cho KJ, Edwards CC 2nd, Rinella AS. Pseudarthrosis in adult spinal deformity following multisegmental instrumentation and arthrodesis. J Bone Joint Surg Am 2006;88:721-8.

11. O’Brien JR, Yu W, Kaufman BE, et al. Biomechanical evaluation of S2 alar-iliac screws: effect of length and quad-cortical purchase as compared with iliac fixation. Spine (Phila Pa 1976) 2013;38:E1250-5.

12. Sebaaly A, Lahoud MJ, Rizkallah M, Kreichati G, Kharrat K. Etiology, evaluation, and treatment of failed back surgery syndrome. Asian Spine J 2018;12:574-85.

13. Mattei TA, Fassett DR. Low-profile pelvic fixation with sacral alar-iliac screws. Acta Neurochir (Wien) 2013;155:293-7. 